\title{
Preparation and Properties of Silicon- Containing Polymer Hybrids from 3-Methacryloxypropyltrimethoxysilane
}

\author{
Yoshimoto Abe, ${ }^{*}$ Yuki Honda and Takahiro Gunji \\ Department of Industrial Chemistry, Faculty of Science and Technology, Science University of Tokyo, \\ 2641 Yamazaki, Noda, Chiba 278, Japan
}

The preparation of organic-inorganic polymer hybrids consisting of carbon-carbon and siloxane chains was investigated by radical polymerization of 3-methacryloxypropyltrimethoxysilane (MAS) followed by acid-catalyzed hydrolytic polycondensation. The condensation of poly(3-methacryloxypropyltrimethoxysilane) (S-PMA) of various molecular weights $M_{n}=$ 830-12000 prepared by polyaddition provided transparent and flexible free-standing hybrid gel films. The mechanical properties of these films were highly dependent on the carbon-carbon chain length: with an increase in the carboncarbon chain length, the elasticity of gel films increased, while the tensile strength and Young's modulus decreased. Hydrolyzability of S-PMA decreased with an increase in the carbon-carbon chain length, resulting in the formation of rubber-like films with flexibility. (C) 1998 John Wiley \& Sons, Ltd.

Keywords: polymer; silicon; gel; films

Received 21 July 1997; accepted 2 September 1997

\section{INTRODUCTION}

Considerable attention has been focused on organic-inorganic nanocomposites or polymer hybrids which are expected to provide new materials with novel chemical, physical and mechanical properties. ${ }^{1-7}$ In the preparation of composites or hybrids, mixing of organic polymers and inorganic materials is the conventional method for obtaining micro-

\footnotetext{
* Correspondence to: Yoshimoto Abe, Department of Industrial Chemistry, Faculty of Science and Technology, Science University of Tokyo, 2641 Yamazaki, Noda, Chiba 278, Japan.

E-mail: abeyoshi@ci.noda.sut.ae.jp.

Contract/grant sponsor: Sumitomo Foundation
}

scale composites rather than nanoscale ones. Nanostructured materials can be prepared by the sophisticated route of introducing organic polymers into inorganic matrices. Further high performance and functionalizability of hybrid materials will be, however, achieved by the interpenetrating network $(\text { IPN })^{8,9}$ and inorganic-organic polymer hybrid $(\mathrm{IOPH})^{10,11}$ processes, in which a molecular hybrid with organic-inorganic covalent bonds is indispensable to obtain complete miscibility of organics and inorganics at molecular level.

3-Methacryloxypropyltrimethoxysilane (MAS) is one of the potential starting materials for preparation of the hybrid, because it consists of methacrylate and sila-functional alkoxy groups capable of forming carbon-carbon and siloxane chains by polyaddition and hydrolytic polycondensation, respectively. The hydrolysis mechanism and the copolymerization of MAS with silica or methyl methacrylate to prepare bulk gels have been investigated. ${ }^{12-15}$ The preparation and properties of flexible free-standing gel films has not been reported yet.

In this work, the polyaddition followed by hydrolytic polycondensation of MAS according to Scheme 1 was investigated in order to prepare novel hybrids and to clarify the relationship between the structure and physical properties of gel films by the organic-inorganic polymer hybrid process.

\section{EXPERIMENTAL}

\section{Radical polymerization of MAS}

All the reactions were carried out under a dry nitrogen atmosphere. 3-Methacryloxypropyltrimethoxysilane (MAS) $\left(6.20 \mathrm{~g}, 2.5 \times 10^{-2} \mathrm{~mol}\right)$, tbutyl peroxide $\left(0.16 \mathrm{~g}, 1.25 \times 10^{-3} \mathrm{~mol}\right)$ and ethyl lactate were placed in a four-necked flask equipped 


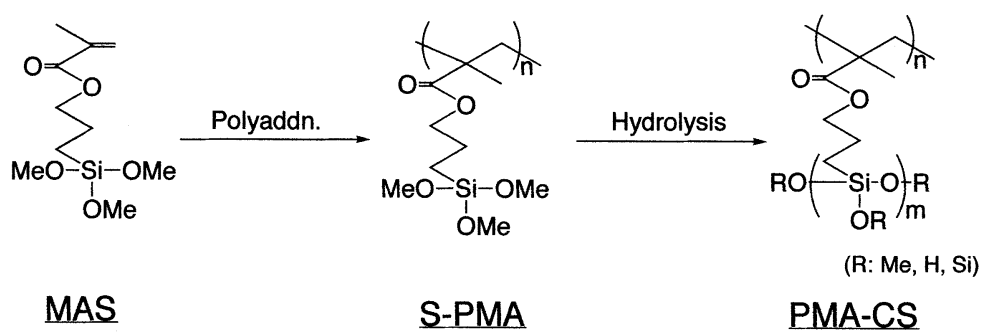

Scheme 1 Preparation of polymer hybrids from MAS.

with a condenser and a stirrer, and then heated to $150{ }^{\circ} \mathrm{C}$ for $2 \mathrm{~h}$. The reaction mixture was cooled with an ice bath for $1 \mathrm{~h}$. After removal of the solvents under reduced pressure, MAS was extracted with $40 \mathrm{ml}$ of hexane. Poly(3-methacryloxypropyltrimethoxysilane) (S-PMA) was isolated as a viscous liquid by drying the hexane-insoluble fraction under reduced pressure.

\section{Preparation of organic-inorganic hybrid gel films}

S-PMA was dissolved in the mixed acetone/ methanol (1:1) solvent as a $20 \mathrm{wt} \%$ solution. The solution was cast on a polymethylpentene plate (90 mm diam.) and heated at $80^{\circ} \mathrm{C}$ for $24 \mathrm{~h}$ in the presence of hydrochloric acid $\mathrm{HCl} / \mathrm{MAS}$ molar ratio $=5 \times 10^{-4}$ to provide a poly(3-methacryloxypropylpolysiloxane) (PMA-CS) gel film.

\section{Instruments and analysis}

${ }^{1} \mathrm{H}$ nuclear magnetic resonance (NMR) spectra in $\mathrm{CDCl}_{3}$ were measured using a JEOL JNMPMX60Si system.

${ }^{13} \mathrm{C}$ Fourier-transformed (FT) NMR spectra in $\mathrm{CDCl}_{3}$ were measured using a JEOL FX-90Q instrument.

Fourier-transformed infrared (FTIR) spectra were recorded using a JEOL JIR-5300 and the instrument $\mathrm{KBr}$ disk method.

The molecular weights were measured by gelpermeation chromatography (GPC). The HPLC system was built by the Nihon Seimitsu Kagaku Co. Ltd. with a reflective index detector made by Nihon Analytical Co. Ltd. RI-3 and columns, Tosoh $\mathrm{G} 3000_{\mathrm{HX}}$ and $\mathrm{G}_{400 \mathrm{HX}}$. Monodispersed polystyrenes were used as standards.

Mechanical properties of the gel films were measured using a Orientec Tensilon/UTM-II-20 system for a test sample $2 \mathrm{~mm}$ wide $\times 20 \mathrm{~mm}$ long.
${ }^{29} \mathrm{Si}$ cross-polarization/magic-angle spinning (CP/MAS) NMR spectra were measured using a JEOL JNM-EX400 instrument. A sample was placed in a wide-bore sample tube $(0.16 \mathrm{ml})$ made from zirconia with an end-cap and rotator made from polyimide (resonance frequency $79.3 \mathrm{MHz}$; Si irradiation power $134 \mathrm{~W}$; irradiation frequency $399.8 \mathrm{MHz}$; $\mathrm{H}$ irradiation power $100 \mathrm{~W} ;{ }^{1} \mathrm{H} 90^{\circ}$ pulse $5 \mathrm{~ms}$; spin lock $50.0 \mathrm{kHz}$; cross-polarization time 5000 ms; spectral width $40000 \mathrm{~Hz}$; pulse repetition time $10 \mathrm{~s}$; MAS rate $6.0 \mathrm{kHz}$; temperature $27^{\circ} \mathrm{C}$. Polydimethylsilane was used as an external standard ( $-34.5 \mathrm{ppm}$ from TMS).

Thermogravimetric differential thermal analysis (TG-DTA) was performed using Rigaku Thermoflex (high-temperature-type) apparatus under an air atmosphere at a heating rate of $10{ }^{\circ} \mathrm{C} \mathrm{min}^{-1}$.

\section{RESULTS AND DISCUSSIONS}

Table 1 summarizes the results on the preparation of polymers having various molecular weights (S-PMA) by the radical polymerization of MAS; they were transparent viscous liquids. The polyaddition of MAS was confirmed by the disappear-

Table 1 Radical polymerization of MAS ${ }^{\mathrm{a}}$

\begin{tabular}{lcrcc}
\hline & & \multicolumn{2}{c}{ Mol. wt } & \\
\cline { 3 - 4 } No. & $\begin{array}{c}\text { Molar ratio } \\
\text { (ethyl lactate/MAS) }\end{array}$ & \multicolumn{1}{c}{$M_{\mathrm{n}}{ }^{\mathrm{b}}$} & $M_{\mathrm{W}} / M_{\mathrm{n}}{ }^{\mathrm{b}}$ & $n$ \\
\hline 1 & 3.53 & 12000 & 5.4 & 48 \\
2 & 7.06 & 5300 & 2.3 & 21 \\
3 & 14.12 & 2600 & 1.5 & 10 \\
4 & 21.18 & 830 & 1.7 & 3.3 \\
\hline
\end{tabular}

${ }^{\mathrm{a}} \mathrm{MAS} 2.5 \times 10^{-2} \mathrm{~mol} ;(\mathrm{tBuO})_{2} / \mathrm{MAS}=5.0 \mathrm{~mol} \%$; polymerization temperature $150^{\circ} \mathrm{C}$; polymerization time $2 \mathrm{~h}$; Yield 55$63 \%$.

${ }^{\mathrm{b}} M_{\mathrm{n}}, M_{\mathrm{w}}$ based on polystyrene standard.

Appl. Organometal. Chem. 12, 749-753 (1998) 


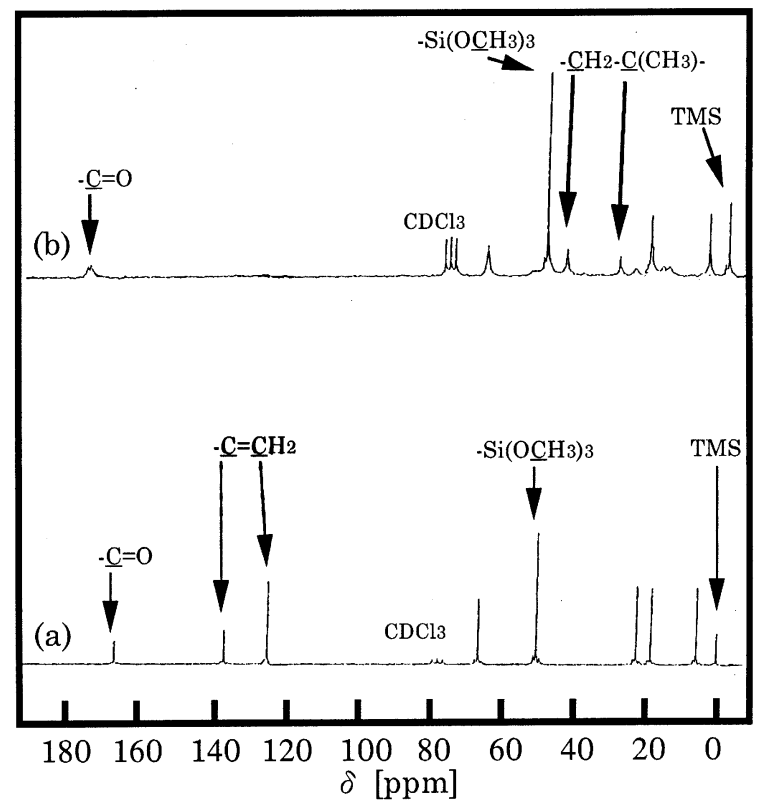

Figure $1{ }^{13} \mathrm{C}$ NMR spectra of (a) MAS and (b) S-PMA. Solvent $\mathrm{CDCl}_{3}$; reference TMS.

ance of the signals due to alkenyl and methylene carbon atoms and the appearance of tertiary carbon atom in the ${ }^{13} \mathrm{C}$ NMR spectra shown in Fig. 1. The molecular weight of S-PMA decreased with the increasing molar ratio of ethyl lactate which acts as a chain-transfer agent to control the molecular weight of S-PMA.

The acid-catalyzed hydrolysis of S-PMA with molecular weights of 2600,5300 , or 12000 for $24 \mathrm{~h}$ at $80{ }^{\circ} \mathrm{C}$ on a polymethylpentene plate gave flexible

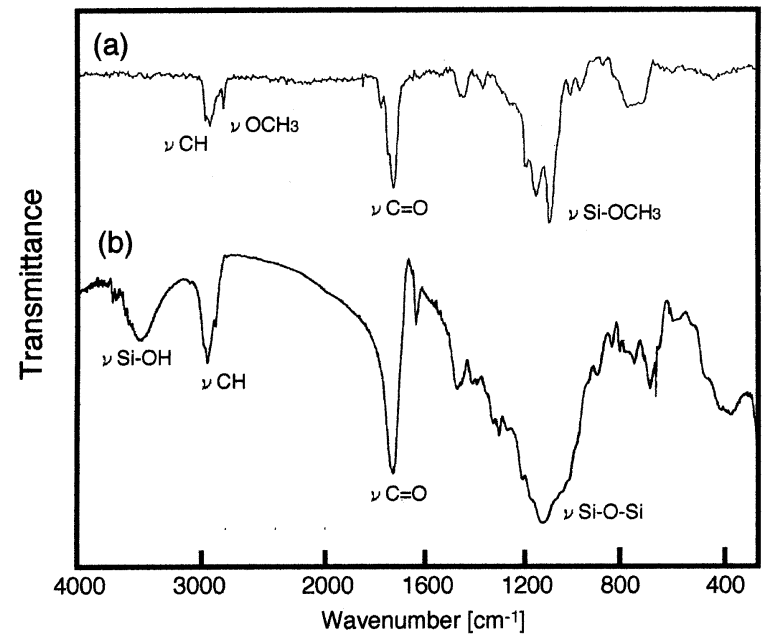

Figure 3 FTIR spectra of (a) S-PMA and (b) PMA-CS gel films. (a) $\mathrm{CCl}_{4}$ solution method; (b) $\mathrm{KBr}$ disk method.

PMA-CS gel films with a thickness of about $20 \mu \mathrm{m}$. The TG-DTA trace of this gel film (Fig. 2) showed marked exothermic peaks at about 400 and $660^{\circ} \mathrm{C}$. The weight losses were $9 \%\left(306^{\circ} \mathrm{C}\right)$ and $47 \%$ $\left(400{ }^{\circ} \mathrm{C}\right)$, which were ascribed to the condensation and the combustion of organic groups, respectively. The total weight loss at $1200^{\circ} \mathrm{C}$ was $66 \%$.

The FTIR spectra of S-PMA and PMA-CS gel films (Fig. 3) show the decrease in the absorption peak intensity due to $v_{\mathrm{OCH} 3}\left(2850 \mathrm{~cm}^{-1}\right)$ and the increase in that due to $v_{\mathrm{SiOH}}\left(3700-3200 \mathrm{~cm}^{-1}\right)$ and $v_{\text {SiOSi }}\left(1200-1000 \mathrm{~cm}^{-1}\right)$, which indicate the hydrolytic polycondensation of S-PMA to afford the hybrid crosslinked by siloxane linkages, PMA-CS gel film. The progress was also monitored by the

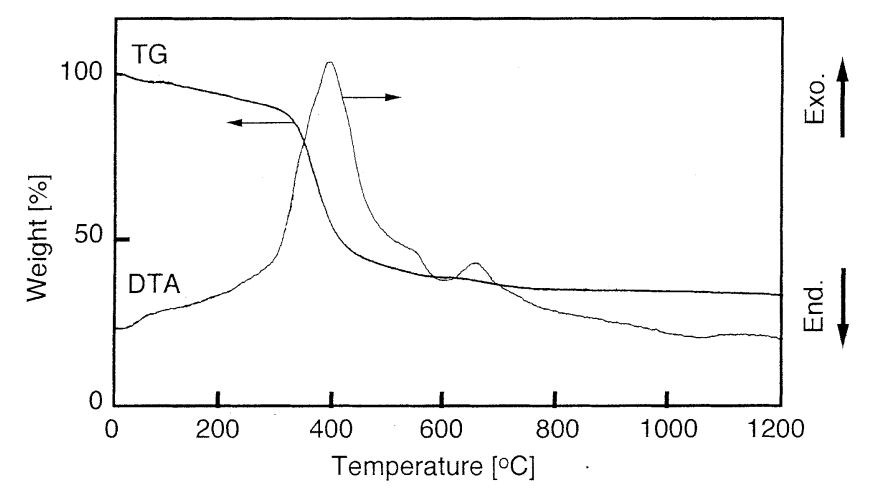

Figure 2 TG-DTA traces of PMA-CS gel film under an air atmosphere. 

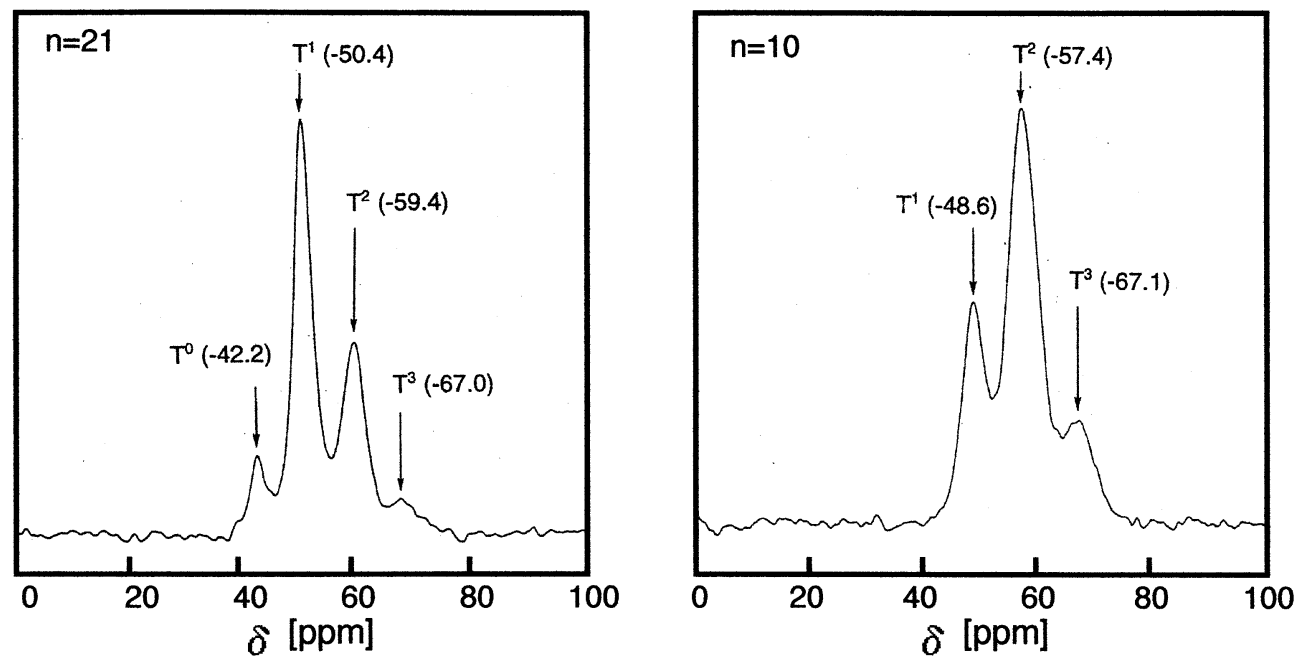

Figure $4{ }^{29} \mathrm{Si}$ CP/MAS NMR spectra of PMA-CS gel films from S-PMA with degrees of polymerization $n=10$ and $21 . \mathrm{T}^{0}$, $\mathrm{RSi}\left(\mathrm{OR}^{\prime}\right)_{3} ; \mathrm{T}^{1}, \mathrm{RSi}\left(\mathrm{OR}^{\prime}\right)_{2}(\mathrm{OSi} \equiv) ; \mathrm{T}^{2}, \mathrm{RSi}\left(\mathrm{OR}^{\prime}\right)(\mathrm{OSi} \equiv)_{2} ; \mathrm{T}^{3}, \mathrm{RSi}(\mathrm{OSi} \equiv)_{3}$.

Table 2 Degree of polymerization $(n)$ and unit structures $\mathrm{T}_{x}$ of PMA-CS gel films

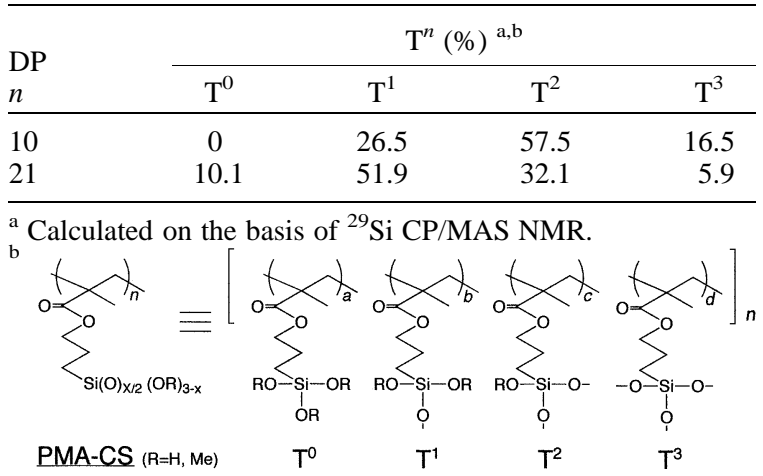

${ }^{29} \mathrm{Si}$ CP/MAS NMR spectra of PMA-CS gel films (Fig. 4) where the signals were observed due to the $\mathrm{T}^{x}$ unit $\left(\mathrm{MeSi}(\mathrm{OSi})_{x}(\mathrm{OR})_{3-x}\right.$ unit: $x$ denotes the number of siloxy groups attached). Table 2 summarizes the composition of $\mathrm{T}^{x}$ units for the PMA-CS gel films prepared from S-PMA with degree of polymerization $n=10,21$. The main siloxane unit in $n=10$ is $\mathrm{T}^{2}$, while it is $\mathrm{T}^{1}$ in $n=21$. The results suggests that the increase in the carboncarbon chain length of S-PMA prevents the hydrolysis because the steric hindrance increases with an increasing degree of polymerization.

Figure 5 shows the maximum stress, maximum elongation and Young's modulus for PMA-CS gel

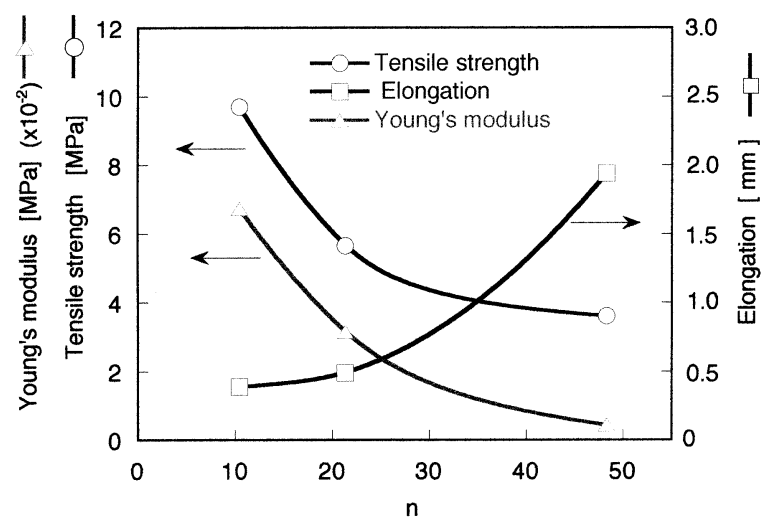

Figure 5 Relationship between mechanical properties and degree of polymerization $(n)$ of PMA-CS gel films.

film. With an increase in the degree of polymerization $(n)$, the maximum stress and Young's modulus decreased, while the maximum elongation increased. The spectral change in Fig. 4 shows good agreement with the behavior in the mechanical properties shown in Fig. 5:S-PMA with a higher degree of polymerization forms a hybrid that is less crosslinked with siloxane linkages and that shows a rubber-like properties, while tough and rigid films are provided from S-PMA with a low degree of polymerization. Therefore, the mechanical properties of the hybrids were found to be controlled by the degrees of contribution of carbon-carbon and siloxane chain. 


\section{CONCLUSION}

Radical polymerization followed by acid-catalyzed hydrolytic polycondensation of S-PMA with various degrees of polymerization in the organic chain provided transparent and flexible free-standing polymer hybrid films consisting of carbon-carbon and siloxane linkages in the molecular main chain. The degree of cross linkage of the siloxane chain is dependent on the degree of polymerization or carbon-carbon chain length: S-PMA with a higher degree of polymerization formed rubber-like hybrids, while tough and rigid hybrids were obtained from S-PMA with lower degrees of polymerization. Thus, the structure of the hybrids is closely related to the mechanical properties.

Acknowledgment This work received financial support from the Sumitomo Foundation. The authors also thank to Sin-Etsu Chemical Co. Ltd for the supply of MAS.

\section{REFERENCES}

1. R. M. Laine, J. A. Rahn, K. A. Youngddahl, F. Babonneau,
M. L. Hoppe, Z.-F. Zhang and J. F. Harrod, Chem. Mater. 2 464 (1990).

2. A. Sellinger and R. M. Laine, Polym. Prepr. 35, 665 (1994).

3. Y. Abe, K. Taguchi, H. Hatano, T. Gunji, Y. Nagao and T. Misono, J. Sol-Gel Sci. Tech. 2, 131 (1994).

4. D. Hoebbel, K. Endres, T. Reinert and I. Pitsch, J. NonCrystal. Solids 174, 179 (1994).

5. Z. Zhang, Y. Tanigami and R. Terai, J. Non-Crystal. Solids 191, 304 (1995).

6. R. H. Baney, M. Itoh, A. Sakakibara and T. Suzuki, Chem. Rev. 1409 (1995).

7. R. Joseph, S. Zhang and W. T. Ford, Macromolecules 29, 1305 (1996)

8. J. R. Millar, J. Chem. Soc. 121, 1311 (1960).

9. H. Schmidt and H. Wolter, J. Non-Crystal. Solids 121, 428 (1990).

10. M. W. Ellsworth and B. M. Novak, Chem. Mater. 5, 839 (1993).

11. B. M. Novak, D. Auerbach and C. Verrier, Chem. Mater. 6 , 282 (1994).

12. N. Nishiyama, K. Horie and T. Asakura, J. Appl. Polym. Sci. 34, 1619 (1987).

13. L. Delattre, C. Dupuy and F. Baboneau, J. Sol-Gel Sci. Tech. 2, 185 (1994)

14. M. S. O'Shea and G. A. George, Polymer 35 (19), 4181 (1994).

15. C. Mai, J. F. Cornu, L. Arnaud and J. Perez, J. Sol-Gel Sci. Tech. 2, 135 (1994). 